\title{
Corrigendum: SPRTN is a new player in an old story
}

\section{Kevin Hiom}

Nat. Genet. 46, 1155-1157 (2014); published online 29 October 2014; corrected after print 12 November 2014

In the version of this article initially published, a sentence on page 1156 stated, "This disease was named SPRTN syndrome," in reference to the genetic syndrome described by Lessel et al. (Nat. Genet. 46, 1239-1244, 2014). However, the article by Lessel et al. did not propose a name for the new syndrome. The error has been corrected in the HTML and PDF versions of the article.

\section{Corrigendum: Identification of recurrent $S M O$ and $B R A F$ mutations in ameloblastomas}

Robert T Sweeney, Andrew C McClary, Benjamin R Myers, Jewison Biscocho, Lila Neahring, Kevin A Kwei, Kunbin Qu, Xue Gong, Tony Ng, Carol D Jones, Sushama Varma, Justin I Odegaard, Toshihiro Sugiyama, Souichi Koyota, Brian P Rubin, Megan L Troxell, Robert J Pelham, James L Zehnder, Philip A Beachy, Jonathan R Pollack \& Robert B West

Nat. Genet. 46, 722-725 (2014); published online 25 May 2014; corrected after print 12 November 2014

In the version of this article initially published, the introductory paragraph mistakenly stated that ameloblasts were "cells in the tooth roots of the upper (maxilla) and lower (mandible) jaw responsible for depositing enamel during tooth development (odontogenesis)." The correct location for human ameloblasts is in the developing tooth. Ameloblasts are the normal cell type that ameloblastoma cells resemble and are responsible for forming the enamel covering on tooth crowns. The error has been corrected in the HTML and PDF versions of the article. 